\title{
Os desafios em formar professores da educação infantil utilizando-se de histórias para o ensino de Matemática
}

\author{
The challenges of training early childhood teachers using stories for \\ teaching mathematics
}

\section{Los desafíos de capacitar a maestros de la primera infancia usando historias para enseñar matemáticas}

\section{Eduonete Souza de Alencar'}

Universidade Federal da Grande Dourados, Faculdade de Educação, Professora Adjunta. http://orcid.org/0000-0002-5813-8702

\section{Aldrin Ckeyde da Cunha}

Universidade Federal da Grande Dourados, Faculdade Intercultural Indígena, Professor Adjunto.

https://orcid.org/0000-0002-5813-8702

Patricia dos Santos de Jesus ${ }^{3}$

Universidade Estadual do Mato do Sul, Mestranda Profissional em Educação Científica e Matemática.

https://orcid.org/0000-0002-3147-9080

Resumo: A formação de professores tem sido um desafio das últimas décadas aos pesquisadores da área de Educação, em específico quando focamos nossas preocupações com a formação continuada de professores da Educação Infantil para o ensino de Matemática, nossa inquietação tornar-se maior em virtude da escassez de pesquisas na área. Assim, nossa investigação analisa uma formação continuada de professores da Educação Infantil que tiveram como processo formativo, além do estudo específico do uso de Literatura infantil para o ensino de Matemática, o desenvolvimento de criação de histórias para o seu ensino. Nosso objetivo foi identificar o conhecimento de professores de Educação Infantil no processo de criação de uma história para o ensino de um conteúdo matemático. A metodologia utilizada para a realização do processo formativo foi o Design Experiment e o referencial

Doutora em Educação Matemática pela Pontíficia Universiade Católica de São Paulo; Mestre em Educação Matemática pela Universidade Bandeirante de São Paulo.

2 Doutor em Educação Matemática pela Universidade Anhanguera; Mestre em Educação Para a Ciência e o Ensino de Matemática pela Universidade Estadual de Maringá.

3 Graduada em Pedagogia pela Universidade Federal da Grande Dourados; mestranda em Educação Científica e Matemática pela Universidade Estadual do Mato Grosso do Sul. 
teórico utilizado para a análise foi o Mathematics Teacher's Specialised Knowledge - MTSK. A coleta de dados deu-se por meio de aplicação de questionário e o desempenho de 5 professoras durante o processo formativo. De modo geral, identificamos que o processo formativo para a criação de histórias promove a reflexão dos docentes sobre os domínios e subdomínios do MTSK, essenciais para que haja um bom desempenho em sala de aula. Consideramos ainda um desafio proporcionar diferentes ações formativas para esse segmento de ensino.

Palavras-chave: Educação matemática. Formação de professores. Educação infantil e Literatura infantil.

Abstract: Teacher training has been a challenge in recent decades for researchers in the field of Education, specifically when we focus our concerns with the continuing training of teachers in Early Childhood Education for teaching Mathematics, our concern becomes greater, given the scarcity of research in the area. Thus, our investigation analyzes a continuous formation of teachers of Infantile Education that had as formative process besides the specific study of the use of Children's Literature for the teaching of Mathematics, the development of creation of stories for their teaching. Our goal was to identify the knowledge of Early Childhood Education teachers in the process of creating a story for teaching mathematical content. The methodology used to carry out the training process was the Design Experiment and the theoretical framework used for the analysis was the Mathematics Teacher's Specialized Knowledge - MTSK. Data collection took place through the application of a questionnaire and the performance of 5 teachers during the training process. In general, we identified that the formative process for the creation of stories promotes the teachers' reflection on the domains and subdomains of the MTSK, essential for a good performance in the classroom. We also consider it a challenge to provide different training actions for this segment of education.

Keywords: Mathematical education. Teacher training. Early childhood education and children's literatura.

Resumen: La capacitación de docentes ha sido un desafío en las últimas décadas para los investigadores en el campo de la educación, específicamente cuando enfocamos nuestras preocupaciones con la capacitación continua de docentes en educación infantil temprana para la enseñanza de las matemáticas, nuestra preocupación se vuelve mayor, dada la escasez de investigación en el área. Así, nuestra investigación analiza una formación continua de docentes de Educación Infantil que tuvo como proceso formativo además del estudio específico del uso de Literatura Infantil para la enseñanza de las Matemáticas, el desarrollo de la creación de cuentos para su enseñanza. Nuestro objetivo era identificar el conocimiento de los maestros de Educación Infantil en el proceso de crear una historia para enseñar contenido matemático. La metodología utilizada para llevar a cabo el proceso de capacitación fue el Experimento de diseño y el marco teórico utilizado para el análisis fue el Conocimiento especializado del maestro de matemáticas - MTSK. La recolección de datos se realizó mediante la aplicación de un cuestionario y el desempeño de 5 docentes durante el proceso de capacitación. En general, identificamos que el proceso formativo para la creación de historias promueve la reflexión de los maestros sobre los dominios y subdominios del MTSK, esencial para un buen desempeño en el 
aula. También consideramos un desafío proporcionar diferentes acciones de capacitación para este segmento de la educación.

Palabras clave: Educación matemática. Formación de profesores. Educación de la primera infancia y literatura infantil.

Recebido em 10 de fevereiro de 2020

Aceito em 30 de setembro de 2020

\section{INTRODUÇÃO}

Nos últimos anos são muitos os esforços que os pesquisadores têm realizado para promover ações formativas que proporcionem efetivamente mudanças na prática. Villa-Ochoa e Alencar (2019) e Barreto e Prado (2018) evidenciam em suas investigações a preocupação com esta temática. Como consequência deste fato o número de pesquisas na última década aumentou consideravelmente sobre a formação de professores que ensinam matemática, conforme aponta mapeamento realizado por Fiorentini, Passos e Lima (2018). Os autores evidenciaram como veem sendo tratado a temática nos últimos anos e quais são as lacunas existentes e que necessitam ser aprofundadas. Observamos que estudos formativos da educação infantil são pouco realizados e por este motivo nos debruçamos a realizar esta investigação com professores neste segmento de ensino e apresentar parte dos dados neste artigo.

Assim, nosso objetivo é identificar quais são os desafios de formar professores para ensinar matemática utilizando como recurso a literatura infantil. Para atingir essa meta realizamos a metodologia Design Experiment em uma ação formativa com 5 professores de Educação Infantil, no qual apresentaremos em uma próxima seção deste artigo.

Ressaltamos ainda que apresentamos dados parciais do projeto "Criação de histórias de Literatura Infantil para o ensino de Matemática que foi financiado pelo Instituto Serrapilheira, que possui parecer favorável do comitê ética sob o número 2.756 .607 e com número de protocolo número 90142518.0.0000.5160.

Com isso organizamos as seções com uma explanação dos referenciais teóricos que sustentam a importância da Literatura infantil para o ensino de matemática e para os processos formativos, o referencial teórico de análise, a metodologia realizada, o processo formativo e os desafios encontrados. 


\section{A LITERATURA PARA O ENSINO DE MATEMÁTICA E OS PROCESSOS FORMATIUOS}

Nossa fundamentação utiliza os estudos de Cerquetti e Albercane (2001), Smole, Diniz e Cândido (2000), Zacarias e Moro (2005), Passos e Oliveira (2008), Reame et al. (2013) e Galperin (2013) que mencionam a importância do trabalho com diferentes metodologias para o ensino de Matemática.

Cerquetti e Albercane (2001) aponta que historicamente a Matemática tem sido vista como uma área de difícil compreensão. A autora considera que o método de ensino pode ser uma das possíveis causas dessa dificuldade. Assim infere-se que as formações de professores realizadas devem evidenciar estudos sobre o conteúdo e de como se ensinar Matemática. Cremos, portanto, que proporcionar momentos formativos com diferentes recursos e reflexões pode ser um dos caminhos para a melhoria e compreensão do ensino.

Nesta mesma vertente, Cândido, Diniz e Smole (2000) mencionam algumas considerações sobre incentivo que o professor deve dar ao se ensinar Matemática, no qual este deve ser um incentivador de uma variedade de ideias e campos de conhecimento, promovendo a curiosidade e permitindo que os estudantes identifiquem diferentes formas de ver a realidade (CÂNDIDO; DINIZ; SMOLE, 2000, p. 9).

Passos e Oliveira (2008) consideram que o uso da Literatura infantil pode ser um recurso para o ensino de Matemática contemplando a variedade de ideias e as diferentes formas de percepção.

Em consonância aos estudos de Passos e Oliveira (2008) as autoras Reame et al. (2013), consideram que a língua e a Matemática promovem a habilidade "de interpretar, analisar, sintetizar" e que estas se complementam. Assim o uso da literatura infantil permite também a expressão de sentimentos, demonstração de ações a análise crítica e a explanação de opiniões. Por tanto, utilizar a Literatura Infantil pode ser interessante e motivador para o ensino da Matemática.

Corroborando os estudos anteriores, Galperin (2013) reafirma que a Literatura Infantil pode ser utilizada como um recurso metodológico que promova uma formação direcionada para as diferentes disciplinas. Do mesmo modo, Zacarias e Moro (2005) mencionam que o trabalho com a Literatura Infantil pode trazer possibilidades e estratégias o ensino da Matemática, promovendo reflexões na formação de professores. 


\section{REFERENCIAL TEÓRICO DE ANÁLISE: MTSK}

0 referencial teórico utilizado para a análise das ações formativas foi o modelo do Conhecimento Especializado em Professores de Matemática - MTSK (Mathematics Teachers' Specialised Knowledge), fundamentado em Carrillo-Yañez, Climent, Miguel Montes, Contreras, Flores-Medrano, Escudero-Ávila, Vasco, Rojas, Flores, Aguilar-González, Ribeiro e MuñozCatalán (2018). Este estudo apresenta, conforme Figura 1 o conhecimento do professor de Matemática em dois domínios e subdomínios, apresentando ainda as crenças e aspectos afetivos.

Figura 1 - Modelo de Conhecimento Especializado do Professor de Matemática, MTSK

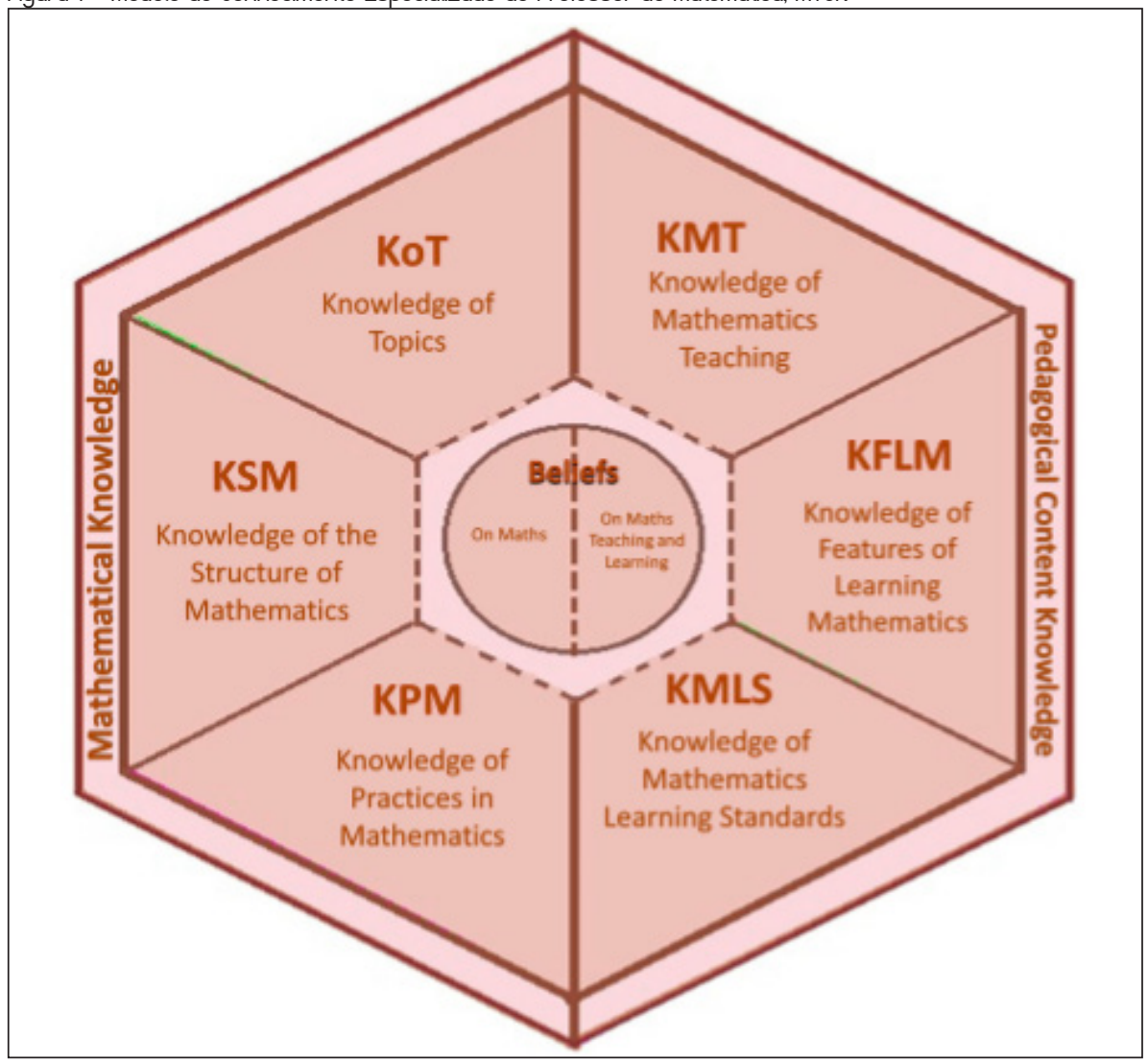

Fonte: Carrillo-Yañez et al. (2018). 
Identificamos na figura sua organização em dois grandes domínios: conhecimento do conteúdo - MK ${ }^{4}$ - e conhecimento pedagógico do conteúdo - PCK.

- 0 Conhecimento Matemático (MK) refere-se ao conhecimento do professor sobre as características e elementos da Matemática. Este domínio é composto pelos subdomínios: Conhecimento dos Tópicos (KOT), Conhecimento da estrutura Matemática (KSM) e o Conhecimento da Prática Matemática (KPM).

- 0 Conhecimento didático do conteúdo (PCK) são os recursos utilizados para o ensino de Matemática, este é composto pelo subdomínio: conhecimento das características da Matemática de Aprendizagem (KFLM), Conhecimento do ensino de Matemática (KMT) e o Conhecimento de padrões de aprendizagem da Matemática (KMLS).

Em relação ao objetivo desse modelo, os autores defendem que:

0 modelo MTSK tem um foco analítico com o objetivo de obter informações sobre o desempenho do conhecimento do professor, especificamente os elementos que vão absorver este conhecimento e as interações entre eles. É, então, preeminentemente direcionado ao estudo do conhecimento, que o professor coloca em uso. Para esse efeito, trazemos domínios e subdomínios sob a hipótese de que o conhecimento em questão possa ser mapeado para eles. Quando dizemos que o professor precisa de conhecimentos relativos a um subdomínio específico, não estamos nos referindo a uma lista de conteúdos; antes, queremos que o professor precise necessariamente ter conhecimento que pode ser localizado neste subdomínio. (CARRILLOYAÑEZ, et al., 2018, p. 4, tradução nossa).

Cabe salientar ainda que todos os subdomínios possuem inter-relações para a promoção do ensino de aprendizagem de Matemática.

\section{DESIGN FORMATIUO: METODOLOGIA}

Utilizamos para esta investigação a metodologia Design Experiments, que, na perspectiva de Cobb et al. (2003), consiste em uma forma peculiar de abordagem de conceitos que

\footnotetext{
4 Todas as siglas deste texto estão em inglês, como referenciado na Figura 1.
} 
envolvem o conhecimento matemático. Estas ações proporcionam desenvolver uma pequena teoria sobre o processo de aprendizagem e quais meios podem ser desenvolvidos. Assim, adaptamos esta metodologia que comumente é utilizada para verificação de aprendizagens em grupo de alunos. Em nosso caso realizamos os procedimentos metodológicos em uma formação de professores e por isso a denominamos de Design formativo.

Nessa metodologia, as hipóteses iniciais poderão ser validadas ou refutadas após a realização das tarefas pelos professores e a realização da primeira intervenção. Assim as tarefas possuem flexibilidade de acordo com que as ações forem demonstrando.

0 resultado da análise dessas etapas deverá promover a elaboração de uma simples e pequena teoria sobre o uso da criação de histórias que envolvem o desenvolvimento do conhecimento matemático, de forma que este estudo seja utilizado posteriormente em outras formações e promovam uma melhor compreensão das ideias que envolvem essa temática.

Com o propósito de obter dados para o nosso estudo, realizamos um encontro semanal de 4 horas com um grupo de professores da rede pública da Educação Infantil. Todo o processo formativo ocorreu durante as reuniões presenciais semanalmente na Universidade Federal da Grande Dourados- UFGD. Não houve seleção dos participantes desenvolvemos o processo formativo com os professores que se inscreveram para a formação. Com isso a realização de nossa investigação foi desenvolvida em seis etapas conforme especificadas na sequência: 1)Aplicação de questionário; 2) Estudo sobre a Literatura infantil e a Matemática e apresentação de uma sequência didática aos professores; 3) Criação de histórias infantis coletivamente para o desenvolvimento de conteúdos matemáticos; 4) Discussão e análise das criações coletivas para reescritas e adequações; 5) Criação das ilustrações e suas análises; 6) Diagramação para e-book animado e para os livros convencionais.

\section{O PERCURSO FORMATIUO E SEUS DESAFIOS}

Nesta seção descrevemos como foi realizado todo o processo formativo, considerando nosso referencial de análise MTSK e os desafios encontrados na formação com este grupo de professores da Educação Infantil.

Como nossa primeira atividade após a apresentação ao grupo foi conhecer o público de professores no qual estávamos formando, por isso aplicamos um questionário contendo as seguintes questões: 
Quadro 1 - Questionário aberto

Você já observou, vivenciou ou utilizou uma história de Literatura Infantil para o ensino de Matemática? Se positivo relate sua experiência

Quais fatores você considera pertinente e/ou não, no uso de histórias de Literatura Infantil para o ensino de Matemática?

Quais conteúdos matemáticos da Educação Infantil você considera importantes serem abordados em histórias de Literatura Infantil? Explique suas considerações

Quais conteúdos matemáticos dos anos iniciais do Ensino Fundamental você considera importantes serem abordados em histórias de Literatura Infantil? Explique suas considerações

Você já criou ou adaptou alguma história infantil para o ensino de Matemática ou outras disciplinas?

Fonte: os autores.

De modo geral, o questionário identificou que 4 professoras de Educação Infantil tiveram contato com relatos ou boas experiências como estudantes ou professoras que envolvessem a Literatura Infantil. Alguns dos relatos mostraram a necessidade de adaptações de histórias para seu uso em matemática, o que é apontado por Zacarias e Moro (2005). De modo geral, evidenciamos o Conhecimento do Ensino da Matemática - KMT, pois demonstrou a percepção que estes docentes possuem sobre a importância de diferentes recursos e estratégias de ensino. Além disso, identificou-se também o conhecimento das características da Matemática de Aprendizagem-KFLM, pois se revelou a proposta interdisciplinar de aprendizagem e suas relações com as teorias de aprendizagem da Psicologia.

Neste questionário ainda identificamos o interesse pelo estudo de determinado tema ou dificuldade e evidenciou-se que as respostas envolviam, localização, sistema de numeração decimal e medidas de tempo.

Com isso ficou evidenciado que o Desafio 1 foi o de conhecer as professoras com o intuito de auxiliá-las em sua formação.

0 segundo momento formativo foi o de estudo sobre a literatura infantil para o ensino de matemática e a apresentação de uma sequência didática aos professores. Este foi dividido em três momentos e com o uso de duas obras e um poema. No livro "0 lobo que virava formas geométricas" de autoria de Edvonete Souza de Alencar e com ilustrações de Antt Pereira pela editora Scortecci (Figura 2), iniciamos a leitura da história utilizando a projeção multimídia e conversamos com as docentes sobre o enredo. Após distribuímos uma folha de papel em branco as professoras para que as estas registrassem as características de cada forma plana citada na história. As respostas das docentes $\mathrm{A}$ e $\mathrm{C}$ nos revelaram as dificuldades que estas possuem a respeito deste conteúdo.

0 que diferencia um quadrado de um retângulo, se algumas das caracteristicas são similares? (DOCENTE A) 
Como consigo identificar as caracteristicas de uma forma geométrica? (DOCENTE C)

Considerando-as realizamos exemplificações e explicações para que as docentes tirassem suas dúvidas e compreendessem o conteúdo. Essa atividade inicial foi necessária para que as docentes percebessem uma das possibilidades do uso da Literatura Infantil para o ensino de Matemática.

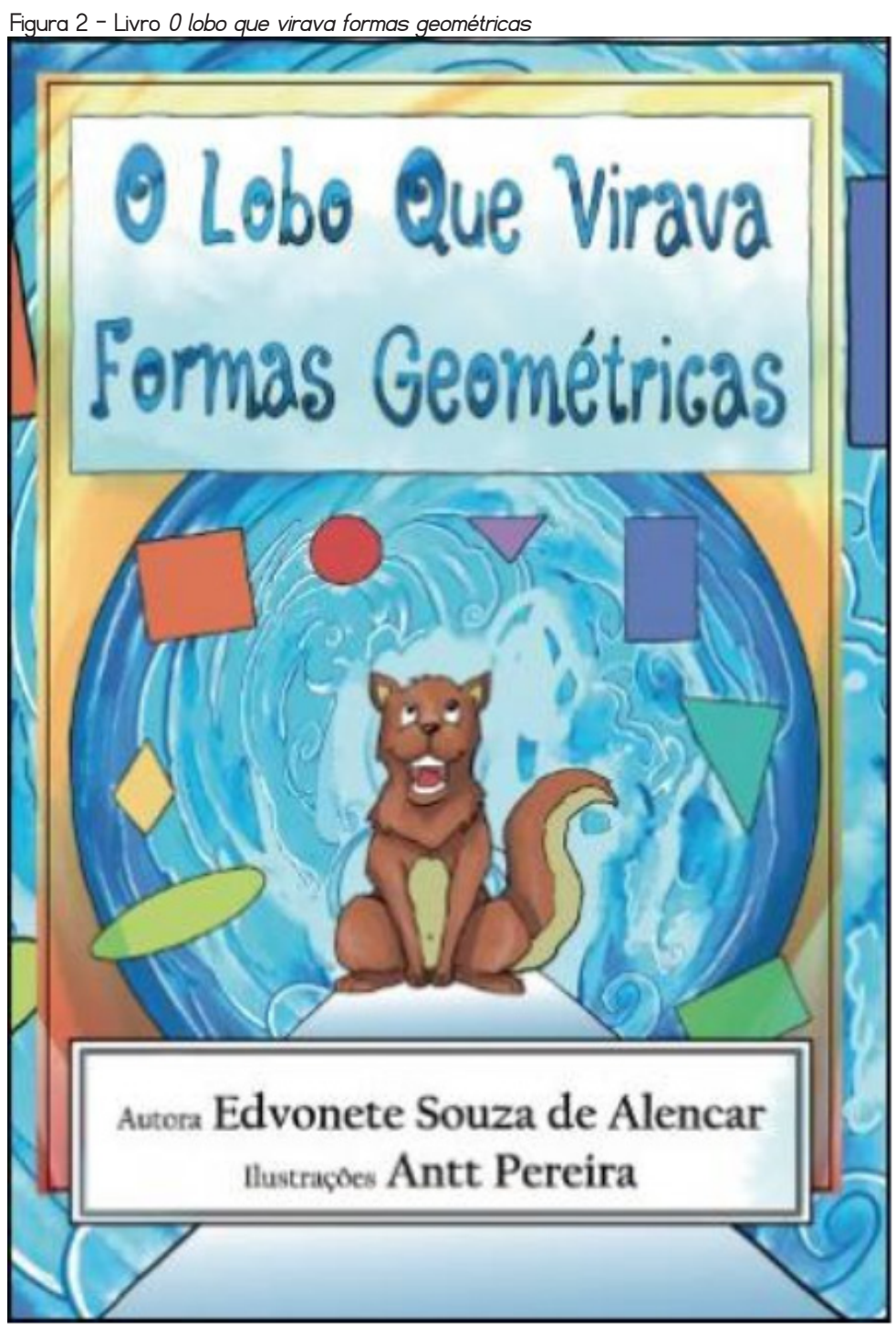

Fonte: Alencar e Pereira (2017). 
Após essa primeira atividade, iniciou-se a leitura do livro "Era uma vez um tatu bola", de autoria de Bia Vilella editorado pela Escala educacional da coleção Sim - Lugares ( figura 3). Nesta história selecionamos alguns trechos para que pudéssemos fazer as análises. Esses trechos revelaram que as docentes não identificavam que o conteúdo de localização faz parte do bloco de conteúdo da geometria. Alguns docentes relataram que sempre pensaram que localização referia-se ao conteúdo de Geografia e não Matemática. Essa afirmação nos fez perceber que os docentes possuem uma dificuldade no KOT (conhecimento dos tópicos).

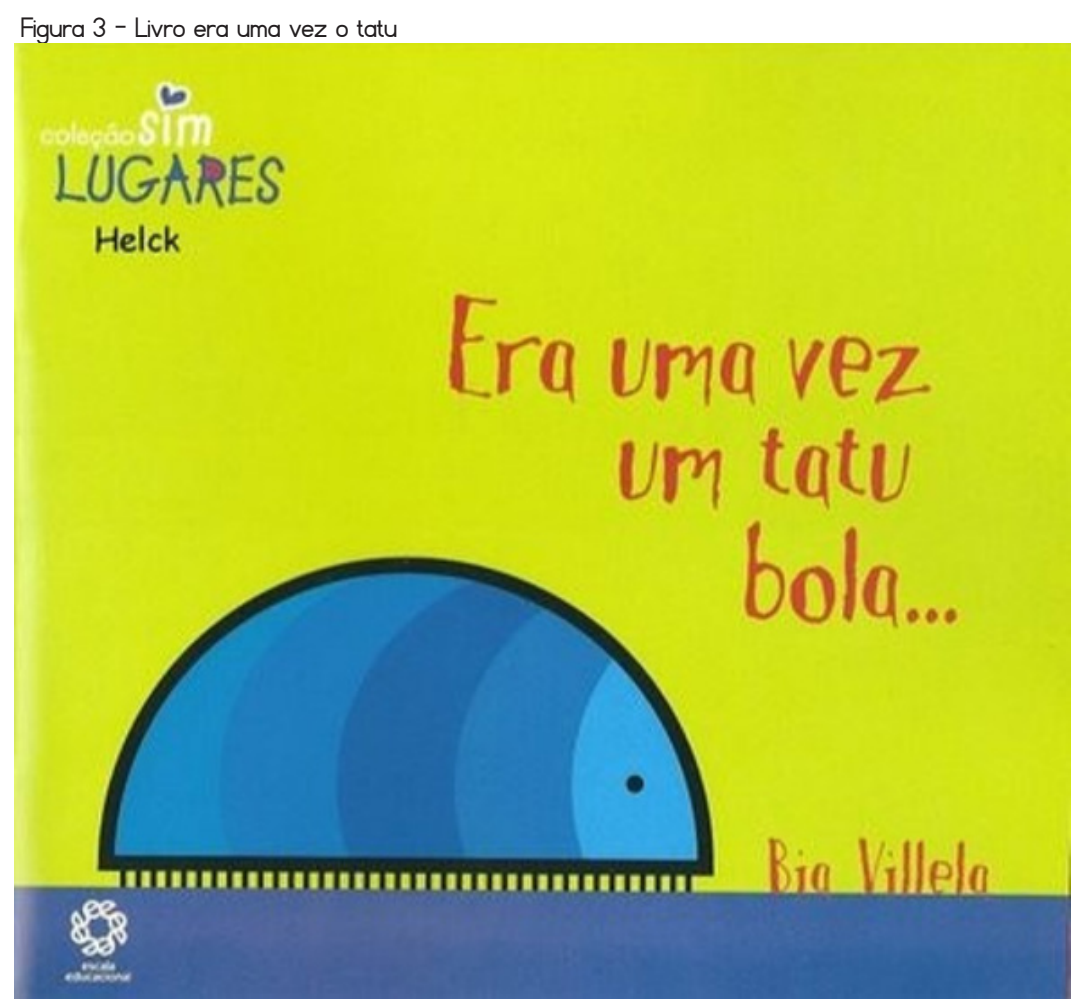

Fonte: Vilella (2007).

No terceiro momento formativo realizamos a leitura do poema Trigonometria amorosa e como tarefa solicitamos que os docentes realizassem desenhos dos personagens dessa história. Selecionamos este poema por trazer diferentes formas geométricas para a reflexão de docentes. Apesar de saber que se trata de professoras que atuam na Educação Infantil, mas que estas possuem uma formação em Matemática mesmo que de Ensino Médio e 
acreditamos que as formações devem potencializar além do saber ensinar e suas reflexões também e primordialmente o conhecimento matemático. Com a realização dos desenhos surgiu dúvidas quanto o que é uma boca trapezoide, o que é um trapézio e este fato nos remete a dificuldade de conhecimento do KOT.

Quadro 2 - Poema Trigonometria amorosa

\begin{tabular}{|c|c|}
\hline TRIGONOMETRIA AMOROSA & Um Perpendicular. \\
\hline Às folhas tantas do livro de Matemática, & Convidaram para padrinhos \\
\hline Um Quociente apaixonou-se & 0 Poliedro e a Bissetriz. \\
\hline Perdidadamente & E fizeram planos, equações e \\
\hline Por uma lncógnita. & diagramas para o futuro \\
\hline "Quem és tu?" indagou ele & Sonhando com uma felicidade \\
\hline Em ânsia radicial. & Integral \\
\hline "Sou a soma do quadrado dos catetos. & E diferencial. \\
\hline Mas pode chamar-me Hipotenusa." & E tiveram muitos filhos: \\
\hline Olhou-a com seu olhar inumerável, do Ápice à Base e viu nela uma & uma secante e três cones \\
\hline figura ímpar: & Muito engraçadinhos. \\
\hline Olhos rombóides, boca trapezóide, & E foram felizes \\
\hline Corpo ortogonal, seios esferóides. & Até aquele dia \\
\hline Fez da sua & Em que tudo se torna, afinal, \\
\hline Uma vida & monotonia. \\
\hline Paralela à dela. & Eis que surgiu \\
\hline Até que se encontraram & 0 Máximo Divisor Comum... \\
\hline No Infinito. & Freqüentador assíduo de Circulos \\
\hline E falando descobriram que eram & Concêntricos e \\
\hline 0 que, em aritmética, corresponde & Viciosos. \\
\hline A alma irmãs & Ofereceu, a ela, \\
\hline Primos-entre-si. & Uma Grandeza Absoluta, \\
\hline E assim se amaram & E reduziu-a a um Denominador Comum. \\
\hline Ao quadrado da velocidade da luz & Ele, Quociente, percebeu \\
\hline Numa sexta potenciação & Que com ela não formava mais um \\
\hline Traçando & Todo, \\
\hline Ao sabor do momento & Uma Unidade. \\
\hline E da paixão & Era o tão chamado Triângulo, \\
\hline Retas, curvas, círculos e linhas senoidais, & amoroso. \\
\hline nos jardins da quinta dimensão & E desse problema, ela era uma fração, \\
\hline Escandalizaram os ortodoxos & a \\
\hline das fórmulas euclidianas & Mais ordinária. \\
\hline E os exegetas do Universo Finito. & Mas foi então que Einstein descobriu a \\
\hline Romperam convenções newtonianas & Relatividade. \\
\hline e pitagóricas. & E tudo que era espúrio passou a ser \\
\hline E, enfim, resolveram se casar. & Moralidade. \\
\hline Constituir um lar. & Como aliás, em qualquer \\
\hline Mais que um lar, & Sociedade. \\
\hline
\end{tabular}

Fonte: Canto da Poesia (2012). 
Com a apresentação dessa sequência didática foi possível identificar ○ Desafio 2 - Conhecer as especificidades das dificuldades em matemática das professoras e auxilia-las na compreensão do mesmo.

Cabe salientar que após essas sequências didáticas, realizamos um estudo do currículo brasileiro e de outros países (Suécia, /Noruega, Portugal, Itália, Espanha, México). Em especial observamos o sistema de numeração decimal e a geometria e o que cada um dos documentos apresentava. Identificamos assim a importância de um trabalho formativo com o estudo do currículo que promoverá o Conhecimento sobre os padrões de aprendizagem em matemática (KMLS).

Neste momento identificamos o Desafio 3 que foi fazer com que as docentes ampliassem o seu conhecimento sobre currículo e que cada pais possui um estrutura de ensino diferente.

A terceira etapa de formação promoveu a Criação de histórias infantis coletivamente para o desenvolvimento de conteúdos matemáticos, no qual os estudos anteriores auxiliaram em seu desenvolvimento. Foram dadas algumas perguntas norteadoras: Como criar uma história? Que personagens criaremos? Que especificidades do conteúdo abordaremos nas histórias?

Percebeu-se ainda no grupo a preocupação de que elementos iriam trazer para a história. As docentes fizeram uma lista de conteúdos e especificidades que a história deveria ter, tal fato nos revela a preocupação com o conhecimento dos tópicos - KOT.

Essa etapa permitiu com que identificássemos o Desafio 4 como proporcionar ações para que os professores desenvolvessem boas histórias.

A quarta etapa foi desenvolver ações para promover a discussão e análise das criações coletivas para reescritas e adequações no texto. Algumas observações foram realizadas como: o uso de determinadas palavras no texto e adequações matemáticas para que houvesse uma melhor compreensão do conteúdo. Acreditamos que essa etapa potencializou o conhecimento pedagógico do conteúdo (PCK) e suas subcategorias.

Neste momento identificou'se o Desafio 5 que foi possibilitar ações aos docentes para que esses fossem atuantes em sua formação, permitindo uma formação diferenciada do padrão comum de estudos teórico e tarefas.

A etapa da Criação das ilustrações e suas análises foi um dos momentos mais dificeis para a formação por que muitas vezes o que o escritor idealiza não é materializado pelo ilustrador o que torna um choque. Os ajustes foram realizados pensando sempre no melhor para a compreensão do aluno. Essa preocupação nos levou a inferir sobre as relações que o docente estabelece com o conhecimento de recursos de aprendizagem da 
matemática - KFLM, visto que as ilustrações podem auxiliar na aprendizagem dos estudantes, possibilitando uma maior compreensão.

Apresentamos a seguir na figura 4 o modelo de uma ilustração e as modificações realizadas.

Figura 4 - Exemplo de análise e adequações das ilustrações do livro As aventuras de Guto

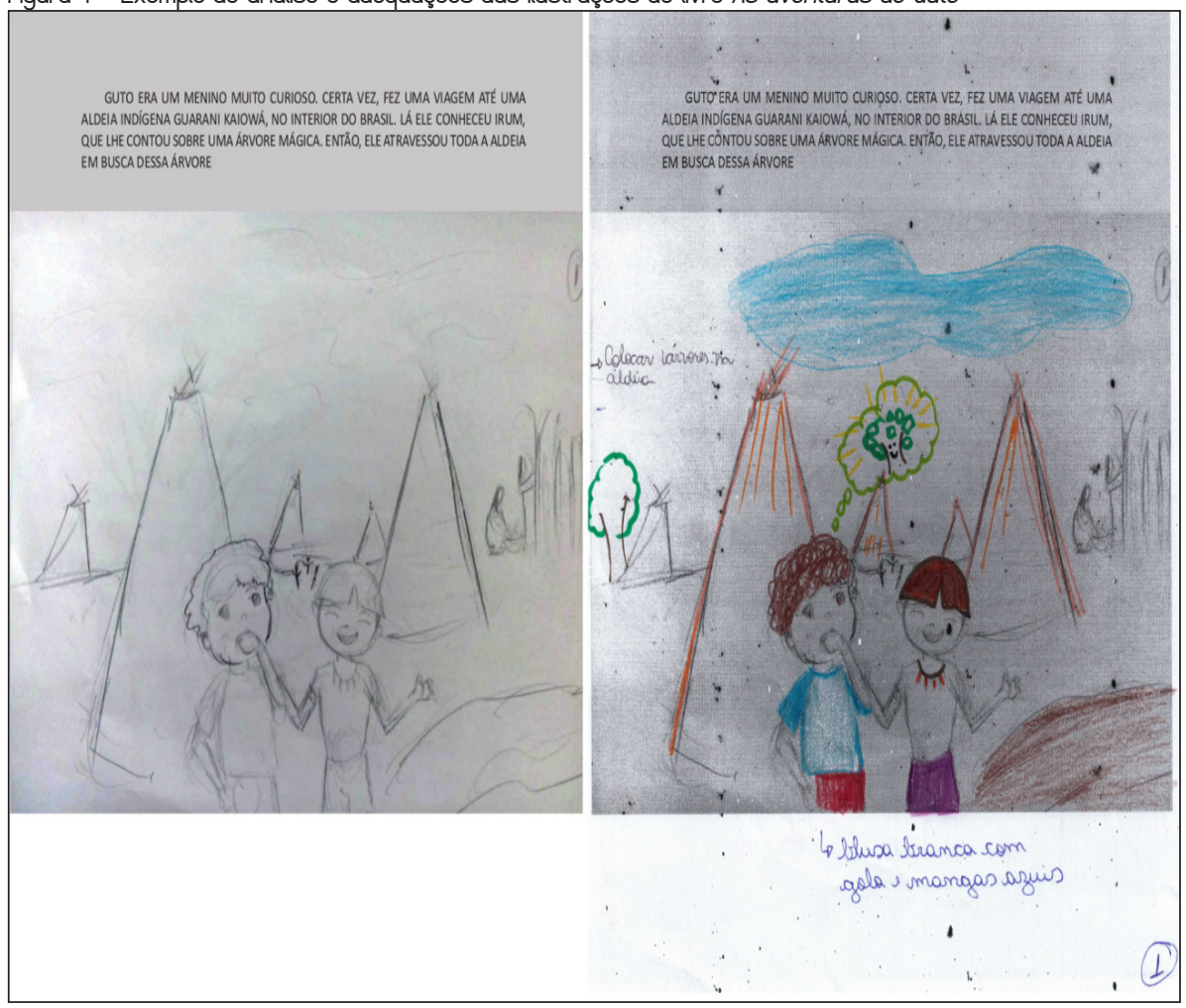

Fonte: os autores.

Na Figura 4 podemos observar como os docentes fizeram suas observações sobre as ilustrações escolha dos tons para a ilustração e adequações de imagens e textos.

0 Desafio 6 foi entrar em um consenso de ideias para que as ilustrações e versões ficassem do melhor modo possível para a compreensão dos conceitos matemáticos.

A última etapa formativa que foi a Diagramação para e-book animado e para os livros convencionais, foi realizada pensando-se nos movimentos dos personagens e que cada página teria, após essa etapa o livro foi disponibilizado no site. 


\section{CONSIDERAÇÕES FINAIS}

Nosso objetivo neste artigo foi identificar quais são os desafios de formar professores para ensinar matemática utilizando como recurso a literatura infantil.

Apresentamos os referencias teóricos, os referenciais de análise, a metodologia e as análises. Especificamente podemos identificar que a criação de histórias pode permitir o incentivo para se gostar mais de ensinar e aprender Matemática, potencializa a construção de um novo olhar para a disciplina.

Algumas docentes relataram mudanças em suas práticas pedagógicas após o a realização da formação. Assim acreditamos que os estudos realizados com os diferentes currículos, as experiências com a sequência didática, como o percurso de criação das histórias foi importante para a reflexão e formação das professoras participantes.

Notamos ainda que os subdomínios do MTSK estiveram presentes em diversos momentos da formação, o que nos faz inferir da importância de aç̃̃es como as desenvolvidas neste projeto para a formação de professores.

Destacamos que os desafios encontrados nessa formação foram:

- Desafio 1: conhecer as professoras com o intuito de auxiliá-las em sua formação;

- Desafio 2: conhecer as especificidades das dificuldades em matemática das professoras e auxilia-las na compreensão do mesmo;

- Desafio 3: fazer com que as docentes ampliassem o seu conhecimento sobre currículo e que cada pais possui um estrutura de ensino diferente;

- Desafio 4: proporcionar ações para que os professores desenvolvessem boas histórias;

- Desafio 5: possibilitar ações aos docentes para que esses fossem atuantes em sua formação, permitindo uma formação diferenciada do padrão comum de estudos teórico e tarefas;

- Desafio 6: entrar em um consenso de ideias para que as ilustrações e versões ficassem do melhor modo possivel para a compreensão dos conceitos matemáticos. 
Analisando o desempenho das participantes durante o processo formativo, podemos concluir que, ao explorar as potencialidades da literatura infantil nessa formação, as professoras puderam criar situações que contribuíram tanto para diálogos teóricos como para o desenvolvimento de vocabulário, noções e conceitos matemáticos. Assim, consideramos que estes desafios podem proporcionar reflexões para outras ações formativas.

\section{REFERÊNCIAS}

ALENCAR, E. S.; PEREIRA, A. 0 lobo que virava formas geométricas. São Paulo: Scortecci, 2017.

BARRETO, M. das G. B.; PRADO, M. E. B. B. P. Um diálogo sobre práticas na formação dos professores que ensinam Matemática. Tangram Revista de Educação Matemática, v. 1, n. 2, 2018.

CANTO DA POESIA. Trigonometria amorosa - uma poesia matemática. ZÉducando, 25 set. 2012. Disponivel em: https://joserosafilho.wordpress.com/2012/09/25/trigonometria-amorosa-uma-poesia-matematica/. Acesso em: 15 abr. 2016.

CARRILLO-YAÑES, J. et al. The mathematics teacher's specialised knowledge (MTSK) model. Research in Mathematics Education, v. 20, p. 1-18, 19 jul. 2018.

CERQUETTI, F.; ALBERCANE, C. B. 0 ensino da matemática na educação infantil. Porto Alegre: Artmed, 2001.

COBB, P. et al. Experimentos de design em pesquisa educacional. Pesquisador Educacional, v. 32, n. 1, p. 9-13, 2003. Disponivel em: http://www.aera.net/uploadedFiles/Journals_and_Publications/Journals/Educational_Researcher/3201/32 01_Cobb.pdf. Acesso em: 8 fev. 2017.

FIORENTINI, D.; PASSOS, C. L. B.; LIMA, R. C. R. Mapeamento da pesquisa acadêmica brasileira sobre o professor que ensina matemática: período 2001 - 2012. Campinas: FE/Unicamp, 2016.

GALPERIN, C. Literatura infantil e a inclusão. In: GOVERNO DO PARANÁ. Secretaria da Educação. Os desafios da escola pública do Paraná na perspectiva do professor PDE. [S. L.: Governo do Paraná, 2013. v. I. Disponivel em: http://www.diaadiaeducacao.pr.gov.br/portals/cadernospde/pdebusca/producoes_ pde/2013/2013_ue np_port_artigo_elizangela_idalgo_regallo_maria.pdf. Acesso em: 8 fev. 2017.

PASSOS, C. L. B.; OLIVEIRA, R. M. M. A. Promoção do desenvolvimento profissional da formação de professores: a produção de histórias infantis com conteúdo matemático. Ciência \& Educação, v. 14, n. 2. p. 315-330, 2008. Disponivel em: http://www.scielo.br/pdf/ciedu/v14n2/a10v14n2. Acesso em: 15 abr. 2016.

REAME, E. et al. Matemática na educação do dia-a-dia das crianças: rodas, músicas, jogos e histórias. 2. ed. São Paulo: Saraiva, 2013. 
SMOLE, K.; DINIZ, M. I.; CÂNDIDO, P. Resolução de Problemas, Coleção Matemática de 0 a 6 . Porto Alegre: Artmed, 2000. v. 2.

VILELLA, B. Era uma vez o tatu bola. [S. ll: Editora Escala educacional, 2007. Coleção Sim - Lugares.

VILLA-OCHOA, J. A.; ALENCAR, E. S. Profesores de matemáticas: investigación sobre los saberes, competencias y modelos para su formación profesional. Uni-pluriversidad, v. 19, n. 2, p. 10-16, dec. 2019. D01: https://doi.org/10.17533/udea.unipluri.19.2.01. Disponivel em: https://aprendeenlinea.udea.edu.co/ revistas/index.php/unip/article/view/339854. Acesso em: 9 fev. 2020.

ZACARIAS, E;; MORO M. L. F. A matemática das crianças jovens e literatura infantil. Educar Curitiba, $n$. 25, p. 275-299, 2005.

Endereço para correspondência: Rodovia Dourados/Itahum, Km 12, Unidade II, Caixa Postal: 364, 79.804-970, Dourados, Mato Grosso do Sul, Brasil; edvonete.s.alencar@hotmail.com 